\title{
Daphnane diterpene hirsein B downregulates melanogenesis in B16 murine melanoma cells by cAMP pathway inhibition
}

\author{
Myra O Villareal ${ }^{1}$, Junkyu Han ${ }^{1,2}$, Kenjiro Ikuta ${ }^{3}$, Hiroko Isoda ${ }^{1,2^{*}}$ \\ From 22nd European Society for Animal Cell Technology (ESACT) Meeting on Cell Based Technologies \\ Vienna, Austria. 15-18 May 2011
}

\section{Background}

Skin pigmentation serves as protection against ultraviolet-induced skin damage through melanin's optical and chemical filtering properties [1]. Although melanin plays and important role in skin protection, excessive melanin production or hyperpigmentation may lead to skin cancer. Recently, the inhibition of melanogenesis has been considered as a valid therapeutic target for the management of advanced melanotic melanomas [2] which increases the need for melanogenesis inhibitors that are of plant origin and are not cytotoxic to mammalian cells. The biosynthesis of the pigment melanin is catalyzed by the melanogenic enzymes tyrosinase, tyrosinase related protein 1 and the dopachrome tautomerase, the transcriptional regulation of which is being regulated by the microphthalmia associated transcription factor (Mitf) [3]. Previously, we have reported that hirsein B (HB) or $5 \beta$-hydroxyresiniferonol- $6 \alpha, 7 \alpha$-epoxy- $12 \beta$-coumaroyloxy-9,13,14-ortho-decanoate from Thymelaea hirsuta [4] has antimelanogenesis effect (without cytotoxicity) on B16 murine melanoma cells by downregulating the expressions of the Mitf gene and the melanogenic enzymes' genes [5]. The exact mechanism by which hirsein B inhibited the Mitf gene expression, however, has not yet been determined. In melanogenesis, the Mitf gene expression can be regulated through the cAMP pathway or the Wnt signaling pathway. This study aimed to determine the mechanism underlying the inhibitory effect of HB on Mitf gene in B16 murine melanoma cells.

\footnotetext{
* Correspondence: isoda.hiroko.ga@u.tsukuba.ac.jp

${ }^{1}$ Graduate School of Life and Environmental Sciences, University of Tsukuba,

Tennodai 1-1-1, Tsukuba, Ibaraki, 305-8572, Japan

Full list of author information is available at the end of the article
}

\section{Materials and methods}

Total RNA was isolated from B16 murine melanoma cells (Riken Cell Bank, Tsukuba, Japan) and used for DNA microarray analysis, using chips of 528 spots loaded with 265 genes prepared by Genopal ${ }^{\mathrm{TM}}$ (Mitsubishi Rayon Co., Ltd, Tokyo, Japan), to determine the expressions of genes for melanogenesis, membranebound receptors, tyrosine kinase regulation, melanosome transport, and other cell signal regulation-related genes (including the housekeeping and negative control genes). To validate the results, real-time PCR, using TaqMan FAST 7500 (Applied Biosystems, Foster City, CA, USA) and specific TaqMan primers (Applied Biosystems, Foster City, CA, USA) for the differentiallyexpressed genes, was performed.

\section{Results}

Results showed that the expressions of the Mitf gene and the melanogenic enzymes' genes were downregulated, verifying our previous report [5]. In addition, the expression of the gene for melanocortin 1 receptor (Mc1r) of the cAMP pathway was downregulated while most of the genes that were upregulated are those involved in the Wnt signaling pathway (Table 1).

In mouse, peptide hormones from the pituitary gland bind to the $M C 1 R$ and stimulate melanin production through the cAMP/PKA signalling pathway [6], by inducing changes in the protein phosphorylation and gene expression, through the MITF gene product.

\section{Conclusions}

The results obtained suggest that the significant antimelanogenesis effect of hirsein B is through the inhibition of the expression of the Mc1r gene of the cAMP pathway. HB may therefore be used as a treatment for

(c) 2011 Villareal et al; licensee BioMed Central Ltd. This is an open access article distributed under the terms of the Creative Commons 
Table 1 Differentially-expressed genes in hirsein B-treated B16 murine melanoma cells as determined by DNA microarray.

\begin{tabular}{ccc}
\hline Biological Process & Differentially expressed genes & Up- or Down- regulated \\
\hline Melanin biosynthesis & Mitf, Mc1r & Downregulated \\
Melanosome transport & Rab27a, Mlph, Myo5A, Myo7A & Downregulated \\
Negative regulation of transcription from RNA polymerase II promoter & Sorbs3 & Downregulated \\
Wnt signaling pathway & Ppap2b, Wisp, Kremen1 & Upregulated \\
Cell cycle regulation & Gadd45b, Csnkl & Upregulated \\
Activation of MAPK signaling pathway & Gadd45b, Pxn, Map2k3, Met, Avpi1, Spag9 & Upregulated \\
Cytoskeleton organization & Pxn & Upregulated \\
Protein phosphorylation & Mapkapk3 & Upregulated \\
\hline
\end{tabular}

hyperpigmentation due to its significant melanogenesis downregulation effects in B16 cells or as a pretreatment for melanotic melanomas.

\section{Acknowledgment}

This study was partially supported by the Science and Technology Research Partnership for Sustainable Development (SATREPS).

\section{Author details}

${ }^{1}$ Graduate School of Life and Environmental Sciences, University of Tsukuba, Tennodai 1-1-1, Tsukuba, Ibaraki, 305-8572, Japan. ${ }^{2}$ Alliance for Research on North Africa (ARENA), University of Tsukuba, Tennodai 1-1-1, Tsukuba, Ibaraki, 305-8572, Japan. ${ }^{3}$ Yokohama Corporate Research Laboratories, Mitsubishi

Rayon Co., Ltd, Tsurumi-ku, Yokohama, Kanagawa, 230-0053, Japan.

Published: 22 November 2011

\section{References}

1. Ahene $A B$, Saxena $S$, Nacht S: Photoprotection of solubilized and microdispersed melanin particles. In Melanin, Its Role in Human Photoprotection. Overland Park, KS: Valendmar;Zeise L, Chedekel M, Fitzpatrick TB 1995:255-269.

2. Slominski A, Zbytek B, Slominski R: Inhibitors of melanogenesis increase toxicity of cyclophosphamide and lymphocytes against melanoma cells. Int J Cancer 2009, 124:1470-1477.

3. Slominski A, Tobin DJ, Shibahara S, Wortsman J: Melanin pigmentation in mammalian skin and its hormonal regulation. Physiol Rev 2004, 84:1155-1228

4. Miyamae $Y$, Orlina-Villareal M, Isoda $H$, Shigemori $H$ : Hirseins A and B, daphnane diterpenoids from Thymelaea hirsuta that inhibit melanogenesis in B16 melanoma cells. J Nat Prod 2009, 72:938-941.

5. Villareal M, Han J, Yamada P, Shigemori H, Isoda H: Hirseins inhibit melanogenesis by regulating the gene expressions of Mitf and melanogenesis enzymes. Exp Dermatol 2010, 19:617-627.

6. Busca R, Ballotti R: Cyclic AMP a key messenger in the regulation of skin pigmentation. Pigment Cell Res 2000, 13:60-69.

\section{Submit your next manuscript to BioMed Central} and take full advantage of:

- Convenient online submission

- Thorough peer review

- No space constraints or color figure charges

- Immediate publication on acceptance

- Inclusion in PubMed, CAS, Scopus and Google Scholar

- Research which is freely available for redistribution

Submit your manuscript at www.biomedcentral.com/submit
C Biomed Central 